\title{
Derechos humanos y procesos culturales. Aportes a partir del pensamiento de Joaquín Herrera Flores. ${ }^{1}$
}

\section{Direitos Humanos e procesos culturais. Aportes a partir do pensamento de Joaquim Herrera Flores.}

Manuel E. Gándara Carballido ${ }^{2}$

\begin{abstract}
Resumen:
El texto presenta algunos de los aportes que realiza el pensamiento de Joaquín Herrera Flores, particularmente a partir de su comprensión de los derechos humanos como productos culturales, en la construcción de una teoría crítica de estos derechos. Para ello, se desarrollan en primer lugar los elementos centrales de la teoría de la cultura de Herrera Flores, para luego pasar a las implicaciones que de ella se derivan en la comprensión de los derechos humanos.
\end{abstract}

\section{Palabras clave:}

Derechos humanos; cultura; procesos culturales.

\section{Resumo:}

O texto apresenta algumas das contribuições feitas pelo pensamento de Joaquín Herrera Flores, particularmente da compreensão dos direitos humanos como produtos culturais, na construção de uma teoria crítica desses direitos. Para isso, os elementos centrais da teoria

\footnotetext{
${ }^{1}$ Se desarrollan en este trabajo ideas ya comenzadas a tratar en ponencias realizadas con anterioridad en algunos congresos dedicados al campo cultural.

2 Profesor en el Programa Oficial de Máster en "Derechos Humanos, Interculturalidad y Desarrollo" de la Universidad Pablo de Olavide de Sevilla, España. Licenciado en Filosofía por la Universidad Santa Rosa de Lima, Caracas, Venezuela. Magister en Filosofía de la Práctica por la Universidad Católica Andrés Bello, Caracas, Venezuela. Magister en Derechos Humanos, Interculturalidad y Desarrollo por la Universidad Pablo de Olavide en Sevilla, España. Doctor en Derechos Humanos y Desarrollo por la Universidad Pablo de Olavide, en Sevilla, España. Activista de derechos humanos, dedicado a la educación popular en derechos humanos en Venezuela, donde ha acompañado procesos de formación y organización con comunidades de base y organizaciones sociales. Miembro de la Red de Apoyo por la Justicia y la Paz y del Instituto Joaquín Herrera Flores.
} 
da cultura de Herrera Flores são desenvolvidos pela primeira vez e, em seguida, as implicações que derivam disso na compreensão dos direitos humanos.

\section{Palavras-Chave:}

Direitos humanos; cultura, processos culturais

\section{INTRODUCCIÓN}

Para que lleguen a ser realmente eficaces en un determinado ámbito, es necesario que los derechos humanos sean culturalmente reconocidos por el conjunto de la población, tanto a nivel personal como en las distintas formas de organización que se van gestando en la vida de los países. Este elemento es central, toda vez que una lectura socio-histórica de los derechos humanos deja en clara evidencia que la mera judicialización nacional o internacional de tales derechos no basta para hacerlos efectivos, siendo fundamental avanzar en la construcción de una cultura que se oponga a la insensibilidad existente frente a las distintas violaciones de los derechos de las poblaciones empobrecidas. ${ }^{3}$

En el marco de este debate en torno a los derechos humanos, queremos presentar en este texto algunos aportes que se realizan desde el pensamiento crítico, particularmente en la obra de Joaquín Herrera Flores, en la construcción de una teoría crítica de los derechos humanos. Más concretamente, pretendemos reflexionar sobre su comprensión de los derechos humanos como productos culturales. Veamos...

\section{UNA NUEVA PROPUESTA DE TEORÍA CULTURAL}

Desde el pensamiento crítico entendemos el ámbito de la cultura sin ingenuidades ni idealizaciones, reconociendo que el mismo puede ser útil tanto para la justificación como para la crítica del orden de relaciones sociales imperante. En ese sentido, la cultura puede

\footnotetext{
${ }^{3}$ Cfr. GAllardo, Helio. Derechos Humanos como movimiento social. Bogotá: Ediciones desde abajo, 2006. De este pensador latinoamericano recomendamos también la lectura de Política y transformación social: Discusión sobre Derechos Humanos. Quito: SERPAJ, 2000; Teoría crítica: Matriz y posibilidad de derechos humanos. (David Sánchez Rubio, editor). Murcia, 2008.
} 
estimular la búsqueda de alternativas a lo dado o reforzar la idea de que lo dado constituye la única posibilidad. Contrarios a concepciones cosificantes, que miran el fenómeno cultural como una realidad dada de una vez, al margen del proceso histórico en que es constituido e inmune a las diversas formas de intervención humana, preferimos no hablar de "la cultura", sino de procesos culturales, intentando con ello confrontar cualquier tipo de visión ahistórica y estática, dadas las consecuencias políticas y sociales que de dicha visión se derivan.

\begin{abstract}
Vamos a defender una concepción abierta de lo que comúnmente denominamos cultura. Es decir, una concepción dinámica, creativa, contextualizada y transformadora de las relaciones sociales, psíquicas y naturales en las que vivimos. Una concepción de cultura que procura su criterio de verdad, no en alguna pretensión de objetividad que permita un análisis científico-neutral de los productos culturales y sus formas de transmisión entre generaciones, sino de $s u$ capacidad de generar indignación frente a las injusticias y explotaciones que sufren y han sufrido los seres humanos a lo largo de la historia. ${ }^{4}$
\end{abstract}

De esta forma, no podemos hablar de las culturas al margen de los procesos sociales en que las mismas se constituyen; gracias a que mantenemos relaciones sociales surgen los procesos culturales. Por tanto, desde las relaciones sociales nos aproximamos a la cultura en que dicho conjunto de relaciones sociales se expresa "como marco de representación simbólica que crea sentidos y conforma identidades en ese espacio relacional. Pero la cultura también como emancipación, como crítica y propuesta de alternativa del marco de relaciones dominantes." 5

En ese sentido, optamos por una concepción de lo cultural que promueva y estimule la capacidad de intervención del ser humano sobre su realidad; que contribuya a ver que la misma se va construyendo en el proceso histórico y puede ser transformada, construida, reconstruida a través del quehacer humano, de las luchas sociales. Asumiendo nuestra dimensión histórica y social, los seres humanos, como seres culturales, podemos constatar que los fenómenos en los que participamos no "son" a secas; que también pueden ser de

4 HERRERA FLORES, J. El proceso cultural: Materiales para la creatividad humana. Sevilla: Aconcagua, 2005, p. 18.

${ }^{5}$ HERRERA FLORES, J. Mimeo. S/F. 
otra manera; que devienen según los vamos configurando en los procesos de construcción histórica. "Para nosotros, lo cultural afirma la pluralidad y la creatividad, frente a la unidad y la pasividad; el devenir, frente al ser, la capacidad de transformación por encima de las tendencias a la adaptación a los órdenes existentes." ${ }^{\circ}$ En palabras de Eduardo Galeano, los seres humanos no somos solo lo que somos, sino también lo que hacemos para cambiar lo que somos. ${ }^{7}$

Lo cultural consiste, a un nivel muy general, en nombrar, en hacer explícito al ser humano el mundo que lo rodea. El objetivo básico de toda "reacción" cultural abierta y dinámica consiste en recordarnos una y otra vez que tenemos la posibilidad de crear el ambiente en el que nos movemos, que ese ambiente no es absoluto ni inamovible, que todo depende de nuestra capacidad de llevar a la práctica la potencialidad que tenemos de designar lo que es y lo que debe ser el mundo. Pero para ello tenemos que desprendernos de aquellas dos connotaciones que subyacían a la interpretación que Occidente hace de esa capacidad humana de nombrar las cosas: la existencia de una trascendencia absoluta que nos nombra, y la tendencia a ver el mundo desde una perspectiva dualista que separa la Verdad de las verdades, lo Universal de las particularidades, que hace imperar un Absoluto sobre la relatividad de nuestras existencias. ${ }^{8}$

Lo cultural es, pues, una construcción permanente de nuevas realidades y nuevas significaciones. "Somos en tanto que creamos, en tanto que hacemos para transformar el mundo... Por esta razón, simbolizar -crear signos culturales- tiene un fuerte componente subversivo frente al orden de cosas dominante." "Lo cultural nos permite reconocernos en nuestra capacidad creadora frente al orden de las cosas.

Contra posturas totalizantes y homogeneizadoras, planteamos que la diferencia cultural es el hecho que nos une a todos, dado que los seres humanos somos "animales culturales" que reaccionamos simbólicamente de un modo diferente en función de los entornos de relaciones en los que vivimos. ${ }^{10} \mathrm{~A}$ través de dichas reacciones culturales frente al mundo, por las que buscamos explicar, interpretar e intervenir en la realidad, construimos

6 HERRERA FLORES, J. El proceso cultural: Materiales para la creatividad humana. Sevilla, Aconcagua, 2005, p. 93.

7 Cfr. GALEANO, E. El libro de los abrazos, p. 91. En Línea: http://www.cronicon.net/ paginas/Documentos/paq2/No.9.pdf. Consulta realizada el 1 de mayo de 2013.

8 HERRERA FLORES, J. El proceso cultural: Materiales para la creatividad humana. Sevilla, Aconcagua, 2005, p. 181.

${ }^{9}$ Ibídem, p. 93.

${ }^{10}$ Cfr. Ibídem, p. 57. 
las diversas formas económicas, políticas, estéticas, religiosas, y damos contenido a la acción social. $^{11}$

La continua y compleja construcción de signos, símbolos, representaciones y significados, en que consiste el proceso cultural, tiene como impulso las reacciones que llevamos a cabo frente al entorno de relaciones que mantenemos con los otros, con nosotros mismos y con la naturaleza. Estas reacciones, a su vez, son producto de su inserción en un circuito de reacción cultural que permite a los seres humanos construir los productos culturales necesarios para explicar, interpretar e intervenir sobre dicho entorno de relaciones: de ahí las estrechas relaciones que los procesos culturales mantienen con la actividad política, entendiendo ésta como la praxis de apertura y dinamismo de potencialidades humanas de creación de mundos nuevos. ${ }^{12}$

Todos somos animales culturales, aunque nuestras reacciones culturales sean necesariamente diversas y plurales, dadas las diferencias que nos caracterizan, las distintas posiciones de poder que ocupamos, etc. De esta manera, en las distintas culturas se expresan formas de vida que tienen su origen en la búsqueda por dar respuesta al entorno; por ello, "al existir diferentes y plurales formas de relacionarse con los otros, con nosotros mismos y con la naturaleza, las reacciones culturales serán diferentes, pero nunca inferiores o superiores las unas con respecto a las otras." 13

Desde esta perspectiva y orientados por esta intencionalidad, se plantea la definición del proceso cultural como aquel conjunto de acciones y reacciones simbólicas a través de las cuales intentamos explicar, interpretar e intervenir los diversos entornos de relaciones en los que vivimos.

El proceso cultural de construcción, intercambio y transformación de signos nos permite explicar, "dar cuenta" de los signos a partir de los cuales se actúa de un modo y no de otro en una u otra formación social (aspecto "causal" o "estructural" de lo cultural, dado que hablamos de los signos culturales que recibimos y en los que nos vamos socializando). En segundo lugar, lo cultural nos capacitará para interpretar tal conjunto "recibido" de signos y, como consecuencia de tal interpretación, el trabajo cultural puede capacitarnos para modificar y transformar los contenidos de la acción (aspecto "metamórfico" o "proteico" de lo cultural). Y, en tercer lugar, tales "explicaciones" y tales

11 Cfr. HERRERA FlORES, J. Los derechos humanos como productos culturales. Crítica del humanismo abstracto. Madrid: Catarata, 2005, p. 98.

${ }^{12}$ HERRERA FLORES, J. De habitaciones propias y otros espacios negados. Una teoría crítica de las opresiones patriarcales. Cuadernos Deusto de Derechos Humanos $\mathrm{N}^{\circ} 33$. Bilbao: Universidad de Deusto, 2005, p. 99.

${ }^{13}$ HERRERA FLORES, J. El proceso cultural: Materiales para la creatividad humana. Sevilla: Aconcagua, 2005, p. 13. 
"interpretaciones" serían imposibles si no nos permitieran intervenir colectiva y grupalmente en la realidad en que vivimos. ${ }^{14}$

Este proceso cultural es un proceso continuo de construcción, transformación e intercambio de "signos", que en una determinada situación de poder nos permite reaccionar de manera colectiva frente al entorno en que vivimos, ${ }^{15}$ comprendiendo la realidad y dotando de sentido nuestra acción. Pero este proceso no ocurre en el vacío; no es neutral. Nuestra construcción de signos y representaciones se lleva a cabo de forma diferenciada en el marco de una específica relación de poder que la configura.

Según los concibe Herrera Flores, autor al que venimos siguiendo a lo largo de toda nuestra argumentación, los procesos culturales se conforman a partir de circuitos de reacción cultural, en los que las distintas producciones culturales responden al conjunto de relaciones que los seres humanos mantenemos con los otros seres humanos, con nosotros mismos y con la naturaleza; orientando así nuestras acciones en los entornos sociales, psíquicos y naturales en los que vivimos. ${ }^{16}$ Es en el marco de estos circuitos de reacción cultural donde se va construyendo nuestra concepción de la realidad en sus distintos ámbitos, y no a partir de "alguna naturaleza humana intemporal, de alguna racionalidad absoluta o siguiendo leyes inmutables del desarrollo histórico (como categorías filosóficas cercanas al autoritarismo y al totalitarismo)" ${ }^{17}$ Es en el circuito de reacción cultural donde se conforman las diversas interpretaciones que sobre las relaciones sociales tenemos, en las que hemos sido socializados y a partir de las cuales actuamos.

Optar por hablar de proceso cultural y no de cultura no es una mera modificación terminológica, pues dicha opción responde a la necesidad de tomar en cuenta los contextos específicos en que el fenómeno cultural tiene lugar, tal y como lo exige el "materialismo cultural”. Este criterio “coloca a lo cultural en el ámbito de una teoría de la producción y la reproducción social, especificando los modos a partir de los cuales los productos

14 HERRERA FLORES, J. El proceso cultural: Materiales para la creatividad humana. Sevilla: Aconcagua, 2005, p. 100.

${ }^{15}$ Cfr. Ibídem, pp. 320-321.

${ }^{16}$ Cfr. Ibídem, p. 290.

${ }^{17}$ Ibídem, p. 83. 
culturales sirven para la dominación o para la resistencia contra la misma." 18 Desde esta perspectiva, resulta fundamental atender a los signos culturales, no como manifestaciones que cobran sentido en sí mismas, sino ser capaces de reconocerlos tanto en sus orígenes como en los efectos materiales que de ellos se derivan; identificando las distintas dinámicas sociales en las que tales signos hacen parte, bien de tendencias de dominación, bien de procesos de resistencia.

Nos referimos, más bien, a las relaciones que se dan entre esos productos y las acciones de los seres humanos que las reciben, asimilan y usan para llevar adelante sus vidas cotidianas. El grado cultural de una época o de un país no debe medirse únicamente por la cantidad de productos culturales que se ofrecen en el mercado, sino por la forma en que tales productos influyen en las acciones de los actores sociales que los "consumen", "producen" y "usan". Si el consumo, la producción y el uso se quedan en mera asimilación o tienden a bloquear la capacidad de creatividad, en dicha forma social o en dicha época primará un tipo de cultura reguladora o ideológica. Ahora bien, si se consumen, producen y usan tales productos en aras de la potenciación de las capacidades humanas de creación y transformación, en dicha forma social o en dicha época primará un tipo de cultura emancipadora. ${ }^{19}$

De esta forma, nos parece sumamente fértil el par categorial regulación/emancipación para la comprensión de los procesos culturales, lo que nos permite distinguir entre procesos culturales emancipadores y procesos culturales reguladores; tal distinción se establece en función de si dichos procesos contribuyen o dificultan la capacidad para que los distintos sujetos, individual o colectivamente, puedan reaccionar de manera diferenciada, a partir de sus particulares sistemas de necesidades e intereses, a los contextos de relaciones en que se encuentran situados y a los distintos productos culturales a través de los cuales dichos contextos son representados.

Por otra parte, resulta claro que tales procesos culturales no son fenómenos aislados, susceptibles de ser comprendidos como dinámicas cerradas en sí mismas, pues están siempre en relación con otros procesos culturales. Por ello, según el modo en que se establezca la interacción intercultural entre los diversos procesos, dirá que es posible

\footnotetext{
${ }^{18}$ Ibídem, p. 94.

19 HERRERA FLORES, J. El proceso cultural: Materiales para la creatividad humana. Sevilla: Aconcagua, 2005, p. 96.
} 
distinguir entre procesos culturales dinámicos (emancipadores) y procesos culturales estáticos (reguladores).

\begin{abstract}
Más que ante "culturas", vistas como entidades independientes, autónomas e incomunicables entre sí, en las que se despliegan las identidades cerradas e incomunicables de los individuos y de los grupos, hablamos, pues, de "procesos culturales", es decir, de estructuras dinámicas, abiertas a la interacción, plurales $\mathrm{y}$, por supuesto, inmanentes a los diferentes contextos sociales, económicos, políticos e ideológicos en los que se desarrollan. En fin, hablamos de procesos abiertos a la interacción entre diferentes y plurales formas de vida, en el seno de los cuales construimos, intercambiamos y transformamos signos que nos van a permitir conectar los objetos con los que nos encontramos en el proceso de socialización: ideas, teorías, ideologías, símbolos (una bandera, un himno...) y las acciones humanas que desplegamos (económicas, políticas, sociales, militares....) ${ }^{20}$
\end{abstract}

Los procesos culturales emancipadores, o abiertos, serán aquellos que promueven la interacción con otros procesos culturales; favoreciendo la creación de espacios interculturales de encuentro, donde todos los actores puedan disfrutar de un efectivo acceso a los bienes necesarios para vivir con dignidad y una real posibilidad para formular y hacer valer sus convicciones. Así mismo, se caracterizan por promover el cambio social, posibilitando que los actores participen de dinámicas democráticas radicales, en las que los aspectos formales se combinan con elementos participativos. $^{21}$

Por su parte, los procesos culturales reguladores, se caracterizan por un cierre de los circuitos de reacción cultural, impidiendo a los actores la producción de productos culturales, que les permitan comprender e intervenir en los entornos de relaciones a partir de sus propias necesidades e intereses. Así mismo, al impedir la interacción con otras dinámicas culturales en igualdad de condiciones, han de ser caracterizados como "coloniales". Por último, son procesos cerrados al cambio social, que impiden que los sujetos (individuales o colectivos) construyan sus propios contenidos para la acción social alternativa a los contenidos hegemónicos, restringiendo las dinámicas democráticas a sus aspectos meramente formales. ${ }^{22}$ Así, pues, estos procesos bloquean la acción social

20 HERRERA FLORES, J. El proceso cultural: Materiales para la creatividad humana. Sevilla: Aconcagua, 2005, p. 92.

${ }^{21}$ Cfr. Ibídem, p. 91.

22 Cfr. HERRERA FLORES, J. El proceso cultural: Materiales para la creatividad humana. Sevilla: Aconcagua, 2005, p. 91. 
autónoma de los sujetos, colectivos y grupos culturales, impidiéndoles reaccionar frente a sus entornos, imponiendo a través de recursos simbólicos, materiales, institucionales, etc., un determinado sistema hegemónico que responde a los intereses otros.

De tal manera, reconociendo que los procesos culturales emancipadores se caracterizan por la apertura de los circuitos de reacción cultural, la apertura a otras dinámicas culturales y la promoción del cambio social, en tanto que los procesos culturales reguladores impiden el circuito de reacción cultural; son procesos coloniales y reducen las dinámicas democráticas a sus aspectos formales, resulta claro que los procesos culturales se encuentran atravesados por relaciones de poder, siendo imposible una comprensión de lo cultural que no se corresponda con una concepción de lo político. Desde este enfoque, lo cultural no es el campo de las expresiones elitistas e idealizadas, sino un espacio abierto al conflicto.

Lo cultural no es un terreno armónico. Más bien es un campo de luchas entre diferentes formas de ver y actuar en el mundo. En los "procesos culturales" siempre se da un gran componente de tensión. El más importante de los cuales es el que nos induce a rechazar las formas hegemónicas de regulación, de orden y jerarquía que se nos imponen ideológicamente, y el proceso que nos induce a optar culturalmente por la emancipación, por la diversidad, la pluralidad y las alternativas. En esta tensión cultural estamos situados. Sólo debemos elegir entre dos polos: o aceptar las relaciones dominantes o rebelarnos y proponer alternativas. ${ }^{23}$

Esta misma idea es desarrollada por Joaquín Herrera a través de la noción de los espacios culturales. Entendiendo por espacio cultural el conjunto de explicaciones, interpretaciones e intervenciones sobre los entornos de relaciones en los que viven los seres humanos y a través de los cuales se define y dinamiza una configuración cultural específica; dotando de identidad y favoreciendo la construcción de sentido de quienes en ellos participan. Dichos espacios culturales podrán ser considerados estáticos (reguladores) o dinámicos (emancipadores), en la medida en que promuevan o impidan el intercambio con otras formas de explicar, interpretar e intervenir en la realidad.

\footnotetext{
${ }^{23}$ Ibídem, pp. 181-182.
} 
Genéricamente, los espacios culturales son "los marcos o estructuras abiertas y dinámicas -sean materiales/geográficas, sean mentales/simbólicas- donde, gracias a la voluntad o esfuerzo de encuentro y contacto, se manifiestan, se reproducen y se transforman interactivamente al menos dos procesos culturales". Es decir, de un modo genérico, los espacios culturales son los ámbitos o marcos donde nos encontramos para construir recíprocamente formas de explicar, interpretar e intervenir en el mundo diferenciadas, pero no excluyentes. Desde este punto de vista genérico, un espacio cultural regulador sería aquel que cerraría la posibilidad del encuentro entre, al menos, dos procesos culturales, imponiendo los productos culturales de uno sobre otro. $\mathrm{Y}$ un espacio cultural emancipador, sería aquel cuyo principal objetivo sería la interconexión y el enriquecimiento mutuo a partir del reconocimiento y la praxis cultural conjunta. ${ }^{24}$

A través de estos elementos para la comprensión de la dimensión cultural de los procesos socio históricos, sea a partir de la noción de procesos culturales emancipadores o de la insistencia en crear espacios culturales en los que se ponga en ejercicio una verdadera voluntad de encuentro, se nos ofrece la posibilidad de aproximarnos a los fenómenos culturales sin descuidar las tramas de poder que configuran nuestra realidad; se nos invita a comprender los procesos sin invisibilizar las relaciones jerarquizadas en las que vivimos. Lo cultural es pues, una dimensión ineludible del proceso de emancipación social, y por tanto deberá ser incorporado a la lucha por la liberación:

Lo cultural, pues, en sus aspectos más dinámicos y agresivos, debería ser usado para esa triple estrategia de liberación: en primer lugar, liberar la potencialidad humana de negar y de resistirse ante los órdenes hegemónicos que intentarán imponerse, siempre y en todo momento, ocultando que ellos mismos son también productos culturales, lo cual es peligroso, pues, como tales productos, pueden perfectamente ser criticados y transformados; en segundo lugar, liberar la potencialidad humana de indignación frente a las injusticias y las explotaciones a las que históricamente se han sometido a los seres humanos al incluirlos jerarquizadamente en procesos de división social, sexual, étnica y territorial del trabajo que, mientras privilegian a unos, enflaquecen y empobrecen a otros; $y$, en tercer lugar, liberar la potencialidad de hacer y des-hacer los entornos de relaciones en los que vivimos. ${ }^{25}$

24 HERRERA FLORES, J. El proceso cultural: Materiales para la creatividad humana. Sevilla: Aconcagua, 2005, pp. 275-276.

25 HERRERA FLORES, J. El proceso cultural: Materiales para la creatividad humana. Sevilla: Aconcagua, 2005, p. 60. 
Es a partir de esta concreta forma de concebir lo cultural, con sus implicaciones, potencialidades y desafíos, que Joaquín Herrera hablará de "los derechos humanos como productos culturales", 26

\section{LOS DERECHOS, UNA INVENCIÓN CULTURAL}

Así como entendemos lo cultural de manera "creativa", enfrentado a las concepciones estáticas y desmovilizadoras de "la cultura", nos hemos de aproximar a los derechos reconociendo en ellos reacciones (productos del circuito de reacción cultural) frente a los procesos de subordinación, explotación y exclusión, que en los distintos ámbitos de la realidad se han venido dando en el muy concreto contexto del sistema de relaciones sociales capitalistas. ${ }^{27}$ Los derechos humanos prestarán a lo cultural "el cauce necesario para conectar con las diferentes luchas que las plurales y múltiples formas de vida que pueblan nuestro mundo han realizado en la búsqueda de la dignidad humana."28

Bajo el término "derechos humanos" se recoge, al menos desde la perspectiva occidental, buena parte de las luchas que los seres humanos llevamos adelante para conseguir condiciones de vida digna, "materializándose en la asunción interactiva de deberes para con los demás, para con nosotros mismos y para con la naturaleza."29 Avanzando en esta línea argumental, nos dice Joaquín Herrera:

Para nosotros, los derechos humanos, no pueden entenderse sino como productos
culturales surgidos en un determinado momento histórico como "reacción" -
funcional o antagonista- frente a los entornos de relaciones que predominaban en
el mismo. Es decir, los derechos humanos no deben ser vistos como entidades
supralunares, o, en otros términos, "derechos naturales". Más bien, deben
analizarse como producciones, como artefactos, como instrumentos que desde sus
inicios históricos en la modernidad occidental, fueron instituyendo procesos de
reacción, insistimos, funcionales o antagonistas, ante los diferentes entornos de

${ }^{26}$ HERRERA FLORES, J. Los derechos humanos como productos culturales. Crítica del humanismo abstracto. Madrid: Catarata, 2005.

${ }^{27} \mathrm{Cfr}$. HERRERA FLORES, J. El proceso cultural: Materiales para la creatividad humana. Sevilla: Aconcagua, 2005, p. 18.

${ }^{28}$ Ibídem, p. 18.

${ }^{29}$ HERRERA FLORES, J. El proceso cultural: Materiales para la creatividad humana. Sevilla: Aconcagua, 2005, p. 323. 
relaciones que surgían de las nuevas formas de explicar, interpretar e intervenir en el mundo. ${ }^{30}$

Es en este sentido, a partir de la comprensión de la dimensión cultural propuesta, entendemos los derechos humanos como medios que pueden ser útiles en los procesos de lucha que en distintos contextos procuran el desarrollo y la apropiación de las capacidades y las potencialidades humanas; así, los derechos se entienden como formas de reacción ante entornos de relaciones. Frente al bloqueo del circuito de reacción cultural, formulado como violación de los derechos, se demanda el reconocimiento y la puesta en práctica de tales derechos. Los derechos no son, pues, un a priori; se reconocen por la vivencia de su ausencia.

Los derechos humanos, desde esta perspectiva, son un producto cultural que busca la apertura permanente de los circuitos de reacción cultural, confrontando los procesos de injusta jerarquización del hacer humano. Los derechos, asumidos de esta manera, promoverían verdaderos espacios de encuentro y contacto, de apertura frente a lo diferente, a lo excluido y marginalizado. ${ }^{31}$

Las luchas por los derechos humanos "humanizan" el mundo, ya que apelan a la promoción de las capacidades humanas de transformación y de superación constante de las situaciones que bloquean los procesos culturales y con ellos la obstaculización del despliegue proteico de la naturaleza humana, lo cual es siempre el blanco de las políticas y propuestas culturales autoritarias y totalitarias. Los derechos humanos "humanizan", es decir, proponen la humanización de los seres humanos, pero no porque sean la manifestación de alguna condición humana ancestral que se concreta en un momento espacio/temporal concreto... Los derechos humanos "humanizan", no en sí mismos o por sí mismos, sino porque son el vehículo que los actores sociales antagonistas al orden existente han creado cairológica y convencionalmente para enfrentarse a todo tipo de cierre de los procesos culturales y a todos los obstáculos que los sistemas autoritarios oponen al libre e igual despliegue de la capacidad humana colectiva de crear y transformar el mundo. ${ }^{32}$

30 HERRERA FLORES, J. Los derechos humanos como productos culturales. Crítica del humanismo abstracto. Madrid: Catarata, 2005, p. 98.

${ }^{31}$ Cfr. HERRERA FLORES, J. El proceso cultural: Materiales para la creatividad humana. Sevilla: Aconcagua, 2005, pp. 323-324.

${ }^{32}$ Ibídem, p. 324. 
Entendidos así, como producto cultural, los derechos son una construcción permanente de la voluntad de encuentro; no son algo dado ni nada ya conseguido, son una construcción constante de los actores sociales empeñados en hacer posibles procesos de humanización, enfrentados a toda dinámica de exclusión y explotación, sea ésta en el ámbito social, política, cultural o económico.

Identificados los derechos humanos como un producto cultural, sometido, por tanto, a los procesos históricos, su configuración, la definición sobre qué aspectos de la vida hemos de considerar como derechos, debe permanecer necesariamente abierta y en constante cambio. No se trata de entidades puras e inmutables, sino sometidas a los procesos búsqueda de dignidad propios de la experiencia humana.

\begin{abstract}
Nuestras producciones culturales y, en consecuencia, aquellas con trascendencia jurídica y política, son ficciones culturales que aplicamos al proceso de construcción social de la realidad. Reconocer que nuestras categorías e instituciones se basan en ficciones culturales, no implica degradar su naturaleza de instrumentos o de técnicas adecuadas para llevar a la práctica nuestra concepción de la sociedad. Al contrario, es precisamente una forma de "saber" indagar cuál es su verdadera naturaleza y poner en evidencia que si han sido creadas por seres humanos éstos pueden cambiarlas si lo consideran conveniente y tienen el suficiente poder para ello. Lo que queremos resaltar es algo muy importante: todas estas construcciones están determinadas por la historia y por la labor interpretativa de la humanidad. ${ }^{33}$
\end{abstract}

Los derechos humanos, al igual que el resto de nuestras producciones culturales con capacidad de impactar y gestar realidades en el ámbito político y jurídico, son inventos que formulamos desde nuestra propia experiencia en función de un ideal postulado, y desde las que intervenimos en el proceso de construcción de la realidad ${ }^{34}$.

El reconocerles su condición de invención no implica que los mismos sean menos adecuados en el proceso de construcción social; por el contrario, afirmar los derechos como una invención, una producción, como un proyecto a ser llevado adelante, nos previene de falsas seguridades en las que se incurriría en caso de considerarlos como algo dado. En este orden de ideas se expresa Eugenio Bulygin cuando afirma:

33 HERRERA FLORES, J. La reinvención de los derechos humanos. Colección Ensayando. Ed. Atrapasueños. 2008, p. 40.

${ }^{34}$ Cfr. HERRERA FLORES, Joaquín. Hacia una visión compleja de los derechos humanos. En: El vuelo de Anteo. Derechos Humanos y Crítica de la Razón Liberal. Bilbao: Desclée de Brouwer, 2000, p. 20. 
La fundamentación de los derechos humanos en el derecho natural o en una moral absoluta no sólo es teóricamente poco convincente, sino políticamente sospechosa, pues una fundamentación de este tipo tiende a crear una falsa sensación de seguridad: si los derechos humanos tienen una base tan firme, no hace falta preocuparse mayormente por su suerte, ya que ellos no pueden ser aniquilados por el hombre. ${ }^{35}$

Entender los derechos humanos como un proyecto a ser concretado en la práctica política y cultural de los pueblos, permite reconocer el carácter fundamental que en la consecución de los mismos han tenido y siguen teniendo las diversas luchas sociales libradas por los distintos pueblos a lo largo de la historia; dichas luchas han hecho posible que los derechos sean incorporados a los sistemas jurídicos vigentes, gracias a lo cual es posible exigir su respeto por parte de los Estados.

Asumirlos de esta manera nos permite también atender al hecho de que los derechos están configurados por las condiciones históricas en que surgen y se desarrollan. ${ }^{36}$ Las distintas narrativas que en torno a los derechos humanos circulan no están exentas de los intereses de quienes las construyen y difunden, viéndose sometido su planteamiento a las ideologías de los dueños del discurso. A ello obedece que ciertas formulaciones de derechos humanos pretendan hacerlos ver como meros hechos legales, despolitizándolos y diluyendo así su potencial emancipador.

Frente a una concepción de los derechos reductivamente formalista, capaz de afirmar derechos haciendo abstracción de las condiciones concretas en que los seres humanos viven, se requieren construcciones teóricas que integren en su discurso la necesaria gestación de condiciones que hagan posible transformar los impedimentos sociohistóricos que en cada caso concreto las personas y los pueblos requieren enfrentar, para así poder acceder a sus diferenciadas formas de vida digna. Se tratará de una construcción que, sin pretender establecer de antemano cuáles han de ser esas condiciones y las capacidades necesarias para enfrentarlas, permita reconocer y animar alternativas frente

35 BULYGIN, Eugenio. Sobre el status ontológico de los derechos humanos. 1987, p. 84. En línea: En línea: http://rua.ua.es/dspace/bitstream/10045/10901/1/Doxa4_05.pdf (Consulta realizada el 03/09/2013).

36 Cfr. HERRERA FLORES, Joaquín. Los derechos humanos como productos culturales. Crítica del humanismo abstracto. Madrid: Libros de la Catarata, 2005. 
a los múltiples mecanismos y estructuras de subordinación que la dinámica sociopolítica plantea, fundadas en las asimetrías de poder. En este marco, se plantea que los derechos humanos

\begin{abstract}
Son la consecuencia y la posibilidad de actuar individual y colectivamente por ver reconocidas y puestas en práctica las diferentes y plurales visiones que tengamos de nuestras capacidades y necesidades (esfera política de los derechos), con el objetivo de 'ajustar' (esfera axiológica de los derechos) el mundo a lo que en cada momento y en cada lugar se entienda por dignidad humana (esfera teleológica de los derechos). ${ }^{37}$
\end{abstract}

Ahora bien, a partir de lo expresado, aparece el cuestionamiento sobre cómo discernir entre las distintas alternativas que desde marcos históricos y culturales diferentes y contextos diferenciados se presentan en el proceso de humanización de lo humano: ¿Es posible suponer que todas las alternativas sean igualmente aceptables, en la medida en que puedan explicarse a partir de sus contextos de origen? Al asumir el criterio de riqueza humana Joaquín Herrera Flores responde fijando posición ante eventuales acusaciones de nihilismo:

\begin{abstract}
¿Puede mantenerse algún criterio que permita enjuiciar si una formación social concreta, o si se quiere la humanidad en su conjunto, ha progresado, teniendo en cuenta la realidad de esos Derechos Humanos? Nosotros pensamos que sí existe un criterio: Nosotros pensamos que sí, el de la riqueza humana, acuñado por Marx y reintrepretado por el neomarxismo contemporáneo... Todo bien social o jurídico, será más o menos valioso (hablamos de grado de valor, pues la naturaleza axiológica viene dada por la preferencia generalizable), en la medida en que contribuya al despliegue y enriquecimiento de las capacidades humanas: la sociabilidad, la libertad, la actividad, la conciencia, etc., siendo la superación de los condicionamientos que imposibilitan la apropiación de esas capacidades, por parte de todos, el elemento sustancial de la argumentación contra la alienación y miseria humana... Progreso, en el sentido axiológico, solo aparece cuando ese despliegue formal, sea efectivamente apropiado por todos. No basta, pues, con el reconocimiento; hay que hablar también de apropiación de ese conjunto de necesidades y capacidades que constituyen los Derechos Humanos. ${ }^{38}$
\end{abstract}

Ciertamente, optar por el criterio de riqueza humana exige rechazar todo universalismo "a priori”, toda pretensión universalista que implique la imposición de

37 HERRERA FLORES, J. La riqueza humana como criterio de valor. En: El Vuelo de Anteo. Derechos humanos y crítica de la razón liberal. Colección Palimpsesto 9. Derechos Humanos y Desarrollo. Bilbao: Desclée De Brouwer, S.A., 2000, p. p. 264.

${ }^{38}$ HERRERA FLORES, J. Proyecto Docente e Investigador en el Área de Filosofía del Derecho, Moral y Política de la Facultad de Derecho de la Universidad de Sevilla, S/F, pp. 231-232. 
ciertos criterios como si fueran el patrón y modelo de humanidad. Por el contrario, esta posición defiende un universalismo "a posteriori", de llegada, en el que sea posible a todas las culturas ofrecer sus opciones y discutirlas en un plano de igualdad. ${ }^{39}$ Sin embargo, ello no implica que todo valga lo mismo; no da igual cualquier alternativa:

Nuestra búsqueda consiste en hallar un criterio que exprese la necesidad humana de caminar hacia lo propiamente humano: es decir, la vida, la acción y la lucha por la dignidad... Partiendo de esa concepción íntegra del ser humano, el criterio que nos va a servir para una apelación no colonialista ni imperialista de lo humano universal es el de riqueza humana. Este criterio se despliega del siguiente modo: a) el desarrollo de las capacidades, y b) la construcción de condiciones que permitan la real apropiación y despliegue de dichas capacidades por parte de individuos, grupos, culturas y cualquier forma de vida que conviva en nuestro mundo. ${ }^{40}$

El Criterio de Riqueza Humana formulado por Herrera Flores como parte de su teoría de derechos humanos plantea la necesidad de que el ser humano esté en condiciones de reaccionar frente al entorno de relaciones en que vive. Así, el elemento paradigmático de los derechos humanos lo conformaría "la facultad para gozar del desarrollo de las capacidades humanas objetivadas social e institucionalmente y para apropiárselas, es decir, para ponerlas en práctica siempre de un modo renovado." 41

Coherentemente con su afirmación de los derechos humanos como productos culturales a través de los cuales se restablece el circuito de reacción cultural frente a aquellos contextos sociohistóricos que niegan el acceso a los bienes, tanto materiales e inmateriales, necesarios para la vida humana, el Criterio de Riqueza Humana ofrece un postulado concreto de acción:

Actúa de tal modo que las consecuencias de tu 'antagonismo' frente a los procesos de división social, sexual, étnica y territorial del hacer humano tiendan a la construcción positiva de condiciones reales y concretas que permitan a los seres humanos poder llevar adelante sus vidas accediendo igualitariamente a los bienes necesarios para vivir una vida digna de ser vivida. ${ }^{42}$

${ }^{39}$ Cfr. HERRERA FLORES, J. La reinvención de los derechos humanos. Colección Ensayando. Ed. Atrapasueños. 2008, p. 180.

${ }^{40}$ Ibídem, p. 178.

${ }^{41}$ HERRERA FLORES, J. Los derechos humanos desde la Escuela de Budapest. Madrid: Tecnos, 1989, p. 126.

${ }^{42}$ Ibídem, pp. 80-81. 
De esta manera, es posible un abordaje material de los derechos humanos que incluyendo lo particular-concreto de cada contexto, reconociéndolo y valorándolo en cuanto tiene de condición de posibilidad para impulsar procesos de transformación, apunte al mismo tiempo a un criterio universalizable. A partir de este criterio, se plantea la lucha por los derechos humanos como lucha por la creación de condiciones para que cada actor social pueda definir y desarrollar su proyecto personal y colectivo de vida humana, con lo que formula una propuesta de segundo orden, evitando posiciones paternalistas que sustituyan la autonomía de los sujetos y presupongan los proyectos de vida a que se debe aspirar.

\section{A MODO DE CONCLUSIÓN}

Al comprender los derechos humanos como productos, tal y como los presenta Joaquín Herrera Flores en el marco de su teoría, no existe mayor violación contra tales derechos que impedir que un individuo, un colectivo, o una cultura completa, pueda formular, reivindicar y llevar adelante su idea de dignidad; bien negándoselo directamente a través de un determinado marco normativo, o bien imposibilitando las condiciones para que dicho proyecto individual o social se ponga en práctica. En consecuencia, lo único que debe ser universalizado es el empoderamiento de los sujetos para que puedan reaccionar frente a su entorno de relaciones y construir así sus diferenciados proyectos de vida digna, ${ }^{43}$ pero desde una concepción de dignidad que se entiende de manera diversa en cada contexto socio-histórico. ${ }^{44}$

\footnotetext{
${ }^{43}$ Cfr. Infra, p. 335.

44 Cfr HERRERA FLORES, J. Los derechos humanos como productos culturales. Catarata, Madrid, 2005.
} 


\section{Bibliografía}

BULYGIN, Eugenio. Sobre el status ontológico de los derechos humanos. 1987, p. 84. En línea: http://rua.ua.es/dspace/bitstream/10045/10901/1/Doxa4_05.pdf (Consulta realizada el 03/09/2013).

GALLARDO, Helio. Derechos Humanos como movimiento social. Bogotá: Ediciones desde abajo, 2006.

GALEANO, E. El libro de los abrazos, p. 91. En Línea: http://www.cronicon.net/ paginas/Documentos/paq2/No.9.pdf. Consulta realizada el 1 de mayo de 2013.

GÁNDARA, M. La universalidad de los derechos humanos: el aporte de Joaquín Herrera Flores. En Teoría crítica dos direitos humanos. Belo Horizonte: Editora Fórum, 2011.

HERRERA FLORES, J. Proyecto Docente e Investigador en el Área de Filosofía del Derecho, Moral y Política de la Facultad de Derecho de la Universidad de Sevilla, S/F.

HERRERA FLORES, J. La fundamentación de los derechos humanos desde la Escuela de Budapest. En: Los Derechos Humanos. Una reflexión interdisciplinar (Seminario de Investigación Francisco Suárez). (Directores: Vicente Theotonio y Fernando Prieto). Córdoba: Publicaciones Etea, 1995.

HERRERA FLORES, J. Hacia una visión compleja de los derechos humanos. En: El vuelo de Anteo. Derechos humanos y crítica de la razón liberal. (Ed. Joaquín Herrera Flores). Bilbao: Desclée De Brouwer, 2000.

HERRERA FLORES, J. La riqueza humana como criterio de valor. En: El vuelo de Anteo. Derechos humanos y crítica de la razón liberal. (Ed. Joaquín Herrera Flores). Bilbao: Desclée De Brouwer, 2000.

HERRERA FLORES, J. De habitaciones propias y otros espacios negados. Una teoría crítica de las opresiones patriarcales. Cuadernos Deusto de Derechos Humanos $\mathrm{N}^{\circ} 33$. Bilbao: Universidad de Deusto, 2005.

HERRERA FLORES, J. El proceso cultural: Materiales para la creatividad humana. Sevilla: Aconcagua, 2005.

HERRERA FLORES, J. Los derechos humanos como productos culturales. Crítica del humanismo abstracto. Madrid: Catarata, 2005. 
HERRERA FLORES, J. Cultura y derechos humanos: la construcción de espacios culturales. En: I/C - revista Científica de Información y Comunicación. N 5, 2008.

HERRERA FLORES, J. La reinvención de los derechos humanos. Colección Ensayando. Ed. Atrapasueños. 2008.

HERRERA FLORES, J. El arte como elogio del movimiento. Mimeo.

SANTOS, B. Crítica de la razón indolente. Contra el desperdicio de la experiencia. Bilbao: Desclée de Brouwer, 2003.

Recebido em : 01/11/2017.

Aprovado em: 14/11/2017. 